Supplement of

Impact of anthropogenic and biogenic sources on the seasonal variation of the molecular composition of urban organic aerosol: a field and laboratory study using ultra-high resolution mass 5 spectrometry

Kaspar R. Daellenbach et al.

Correspondence to: André S. H. Prévôt (andre.prevot@psi.ch) and Markus Kalberer (markus.kalberer@unibas.ch) 


\section{Measurement location}

The measurement sites in central Europe are displayed in Fig. S1.

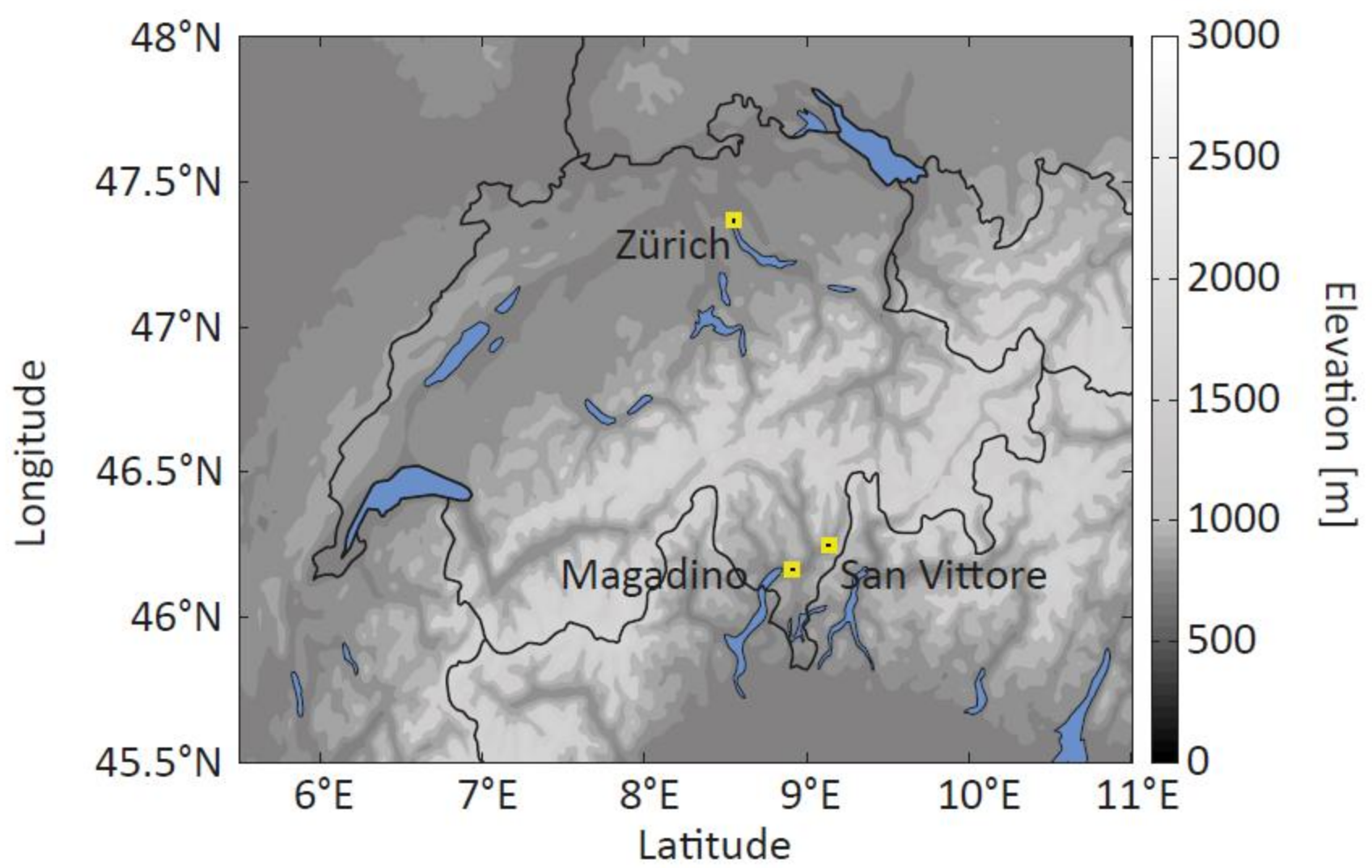

Figure S1: map of Switzerland and surrounding area with marked sampling locations. 


\section{Spatial and temporal variability of biogenic VOC emissions}

Biogenic sesquiterpene and isoprene emissions normalized to biogenic monoterpene emissions are presented in Fig. S3 (as modelled in Jian et al., in prep.).
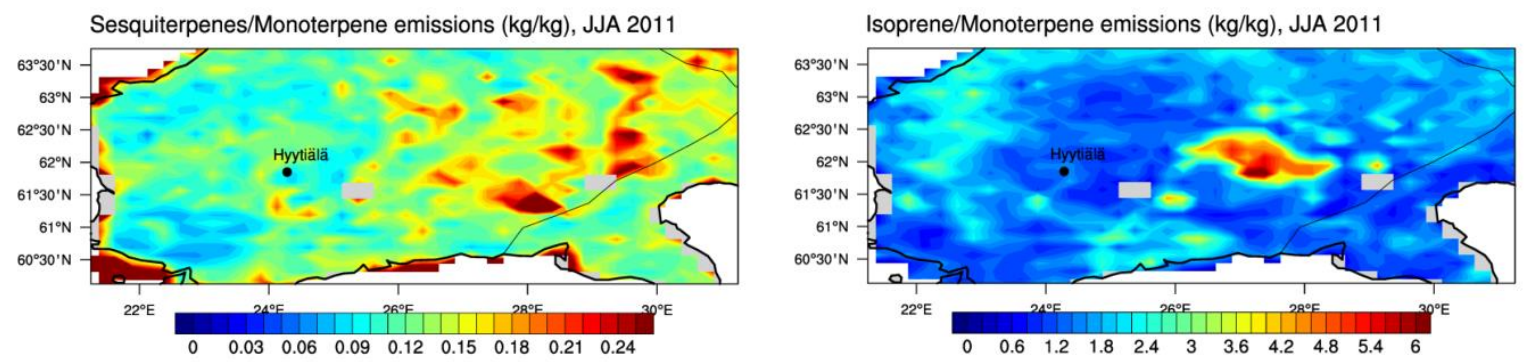

Sesquiterpenes/Monoterpene emissions (kg/kg), JJA 2011

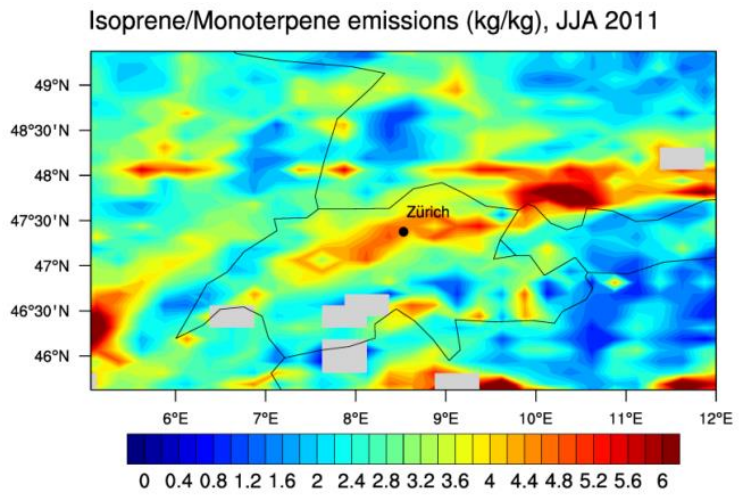

5 Figure S2: biogenic emissions of isoprene (ISO), monoterpene (MT), and sesquiterpenes (SQT) displayed as ratios SQT/MT and ISO/MT for the area (approx. $450 \mathrm{~km} \mathrm{x} 450 \mathrm{~km}$ ) surrounding Zurich, Switzerland, and Hyytiälä, Finland, calculated for summer 2011 using the MEGAN biogenic emission model (Jiang et al., in prep.) 

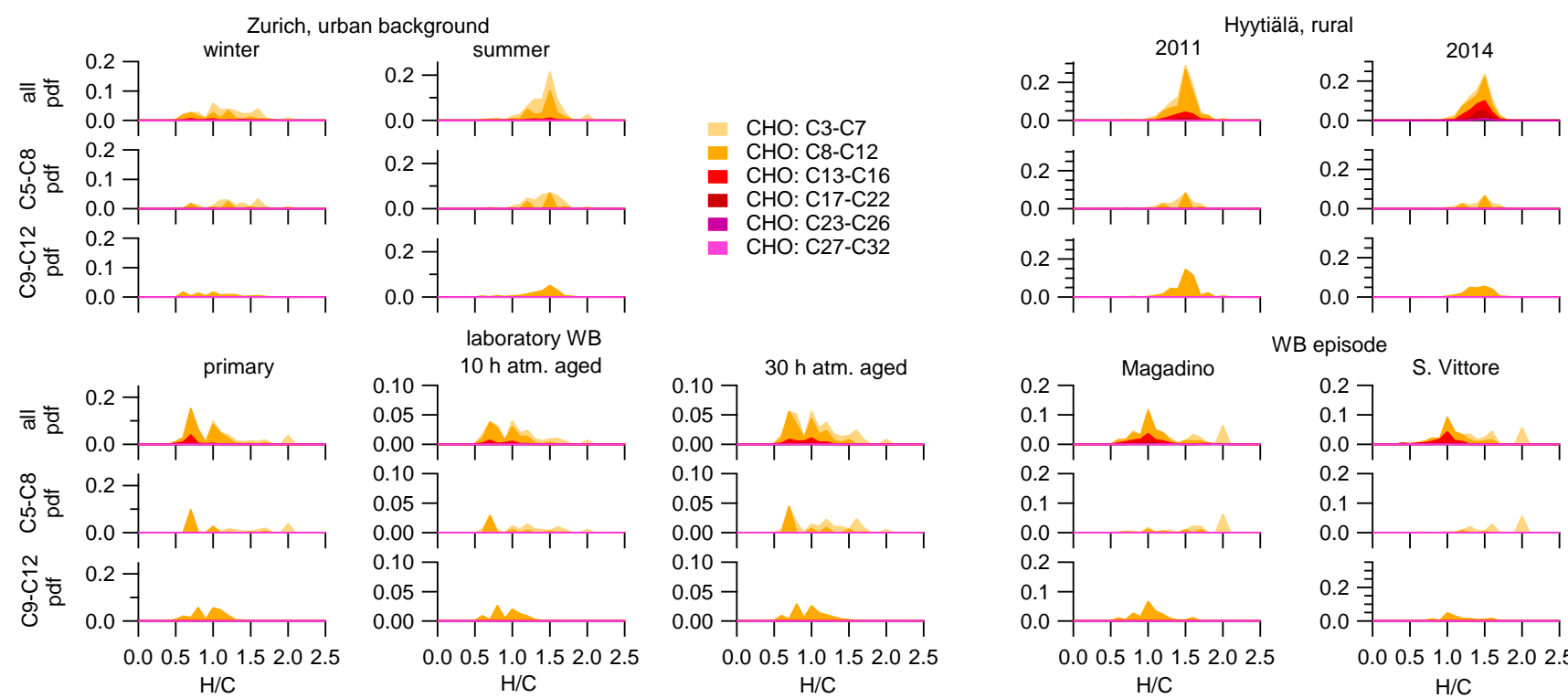

WB episode

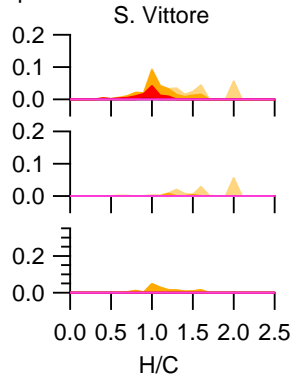

Figure S3: H/C probability density functions (pdf) for all CHO molecules (neutral composition based on (-)ESI-ultra-high resolution mass spectra), molecules with 5 to 8 carbons, respectively 9 and 12 carbon atoms for the ambient samples collected

5 in Zurich, Magadino, S. Vittore, and wood burning smog chamber experiments. The area of the histograms is proportional to the percentage of the total signal explained in the respective site. 


\section{Van Krevelen diagrams color-coded with aromaticity for wood burning influenced samples}

Van Krevelen diagrams of $\mathrm{CHO}$ compounds detected during wood burning smog chamber experiments and at alpine valley sites during wood burning episodes (color-coded with the aromaticity equivalent $\mathrm{X}_{\mathrm{c}}$, Fig S4).
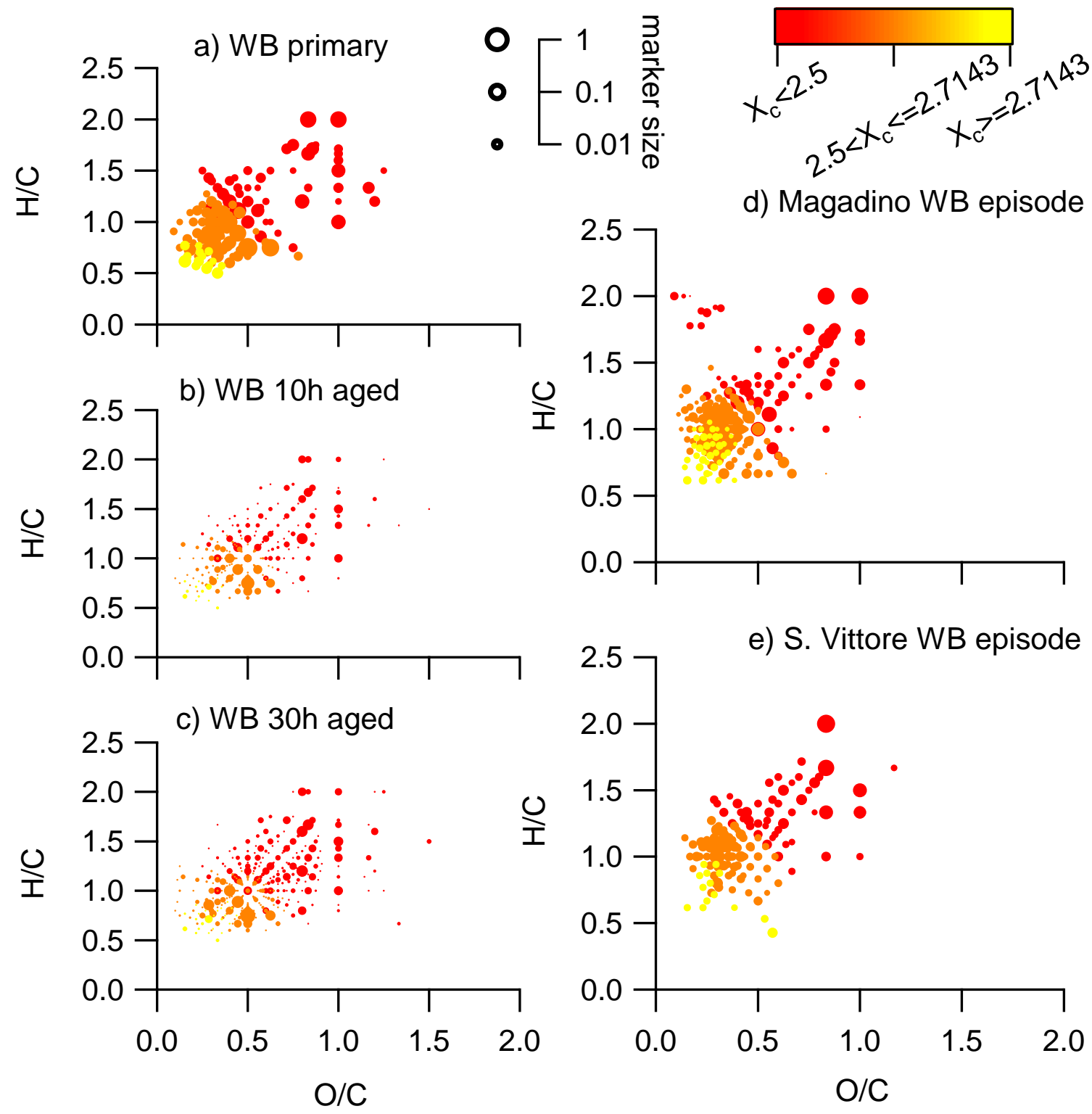

5 Figure S4: Van Krevelen diagrams of negative ion mode spectra (neutral composition) of smog chamber wood burning experiments (fresh emissions, after $10 \mathrm{~h}$ of simulated atmospheric aging, and after $30 \mathrm{~h}$ of simulated atmospheric aging) and wood burning episodes at the alpine valley sites Magadino and S. Vittore. Peaks are displayed as circles with their size reflecting $\log$ (intensity) and the color-code the aromaticity equivalent $X_{c}\left(X_{c}<2.5\right.$ being non-aromatic, $2.5 \geq X_{c}<2.7143$ being aromatic, $X_{c} \geq 2.7143$ being condensed aromatic). 
Van Krevelen diagrams of CHO compounds detected in Zurich (color-coded with the aromaticity equivalent $\mathrm{X}_{\mathrm{c}}$, Fig S5).

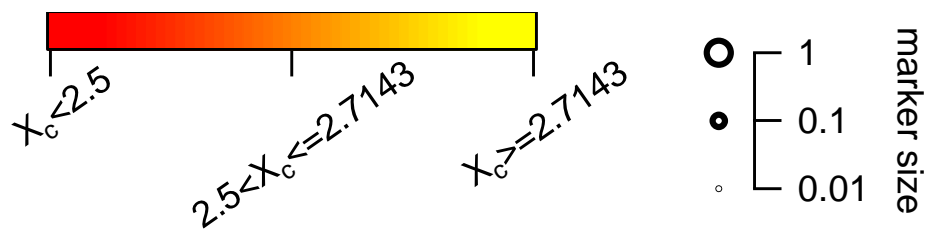

a) Zurich summer
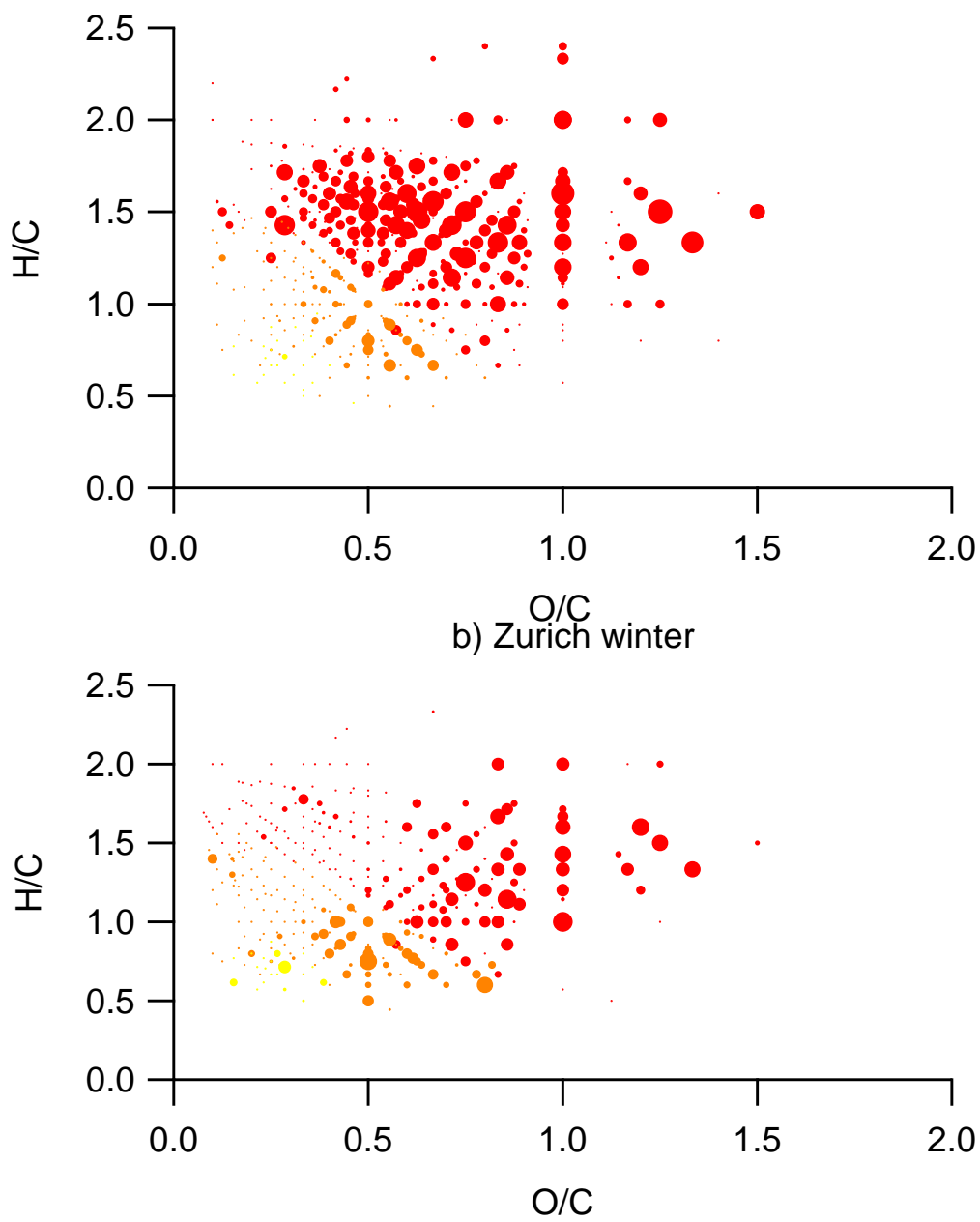

Figure S5: Van Krevelen diagrams of $\mathrm{CHO}$ compounds (neutral composition) of average summer $\left(\mathrm{T}>11^{\circ} \mathrm{C}\right.$, $\mathrm{OA}$ mass-

5 weighted) and winter $\left(\mathrm{T}<6^{\circ} \mathrm{C}\right.$, OA mass-weighted) ultra-high-resolution mass spectra in the negative mode for the organic aerosol in PM10 sampled in Zurich during the year 2013 (weighted average with OA concentration from offline AMS analysis). Peaks are displayed as circles with their size reflecting $\log$ (intensity) and the color-code the aromaticity equivalent $\mathrm{X}_{\mathrm{c}}\left(\mathrm{X}_{\mathrm{c}}<2.5\right.$ being non-aromatic, $2.5 \geq X_{c}<2.7143$ being aromatic, $X_{c} \geq 2.7143$ being condensed aromatic). 
6 Mass spectral signature separated by aromaticity

Spectra of only the CHO compounds for wood burning smog chamber experiments, wood burning episodes at alpine valley sites (Magadino, S. Vittore) and for Zurich during winter (color-coded with the aromaticity equivalent Xc, Fig S6).

CHO: $\mathrm{X}_{\mathrm{c}}<2.5$, I $\mathrm{CHO}: 2.7143>\mathrm{X}_{\mathrm{c}}>=2.5$, । $\mathrm{CHO}: \mathrm{X}_{\mathrm{c}}>=2.7143$

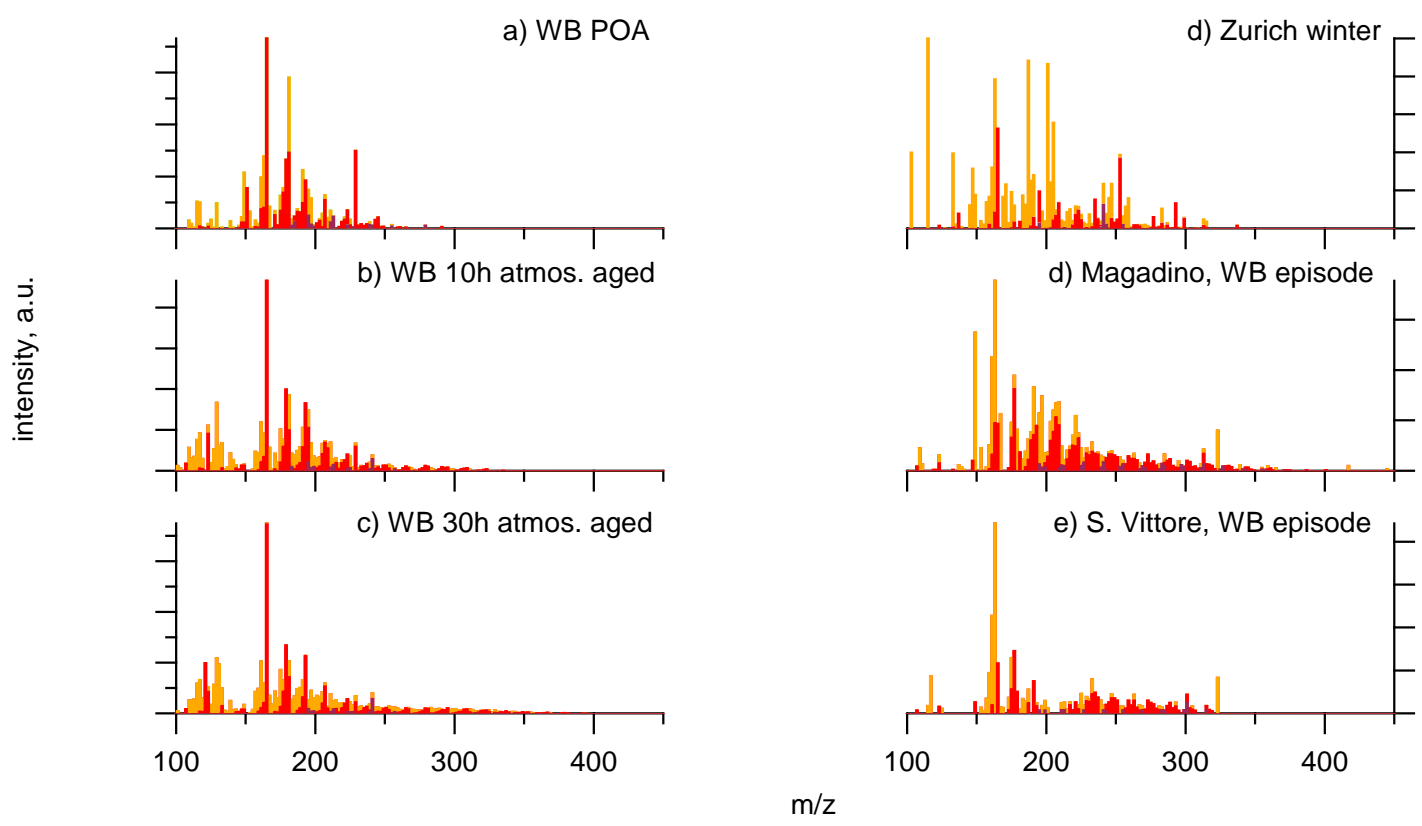

5 Figure S6: ultra-high-resolution mass spectra of $\mathrm{CHO}$ compounds integrated to unit-mass resolution of wood burning laboratory experiments (a: primary emissions, b: emissions 10 hours atmospheric aging, c: emissions 30 hours atmospheric aging), and from winter wood burning episodes at alpine valley sites (d: Magadino, e: S. Vittore). The signal at a nominal mass is separated by ion family (CHON, CHOS, CHONS, other) and the signal of CHO compounds by aromaticity (normal: $\mathrm{X}_{\mathrm{c}}>2.5$, aromatic: $2.5 \leq X_{c}<2.7143$, condensed aromatic: $X_{c} \geq 2.7143$ ). Peak assignments of dominant ions of selected UMR peaks are

10 labelled as neutral compounds. 


\section{Contributions of compound classes to the signal}

The contribution of $\mathrm{CHO}, \mathrm{CHON}, \mathrm{CHOS}$, and CHONS compounds varies as a function of the season and measurement location (Fig. S7).

$$
\begin{aligned}
& \mathrm{CHO} \\
& \mathrm{CHON}
\end{aligned} \mathrm{C3-C7,} \mathrm{C} \text {-C12, C13-C16, C17-C22, }-\mathrm{C} 23-\mathrm{C} 26,-\mathrm{C} 27-\mathrm{C} 32
$$

$\mathrm{CHOS}$

ambient, urban background

Zurich

סั

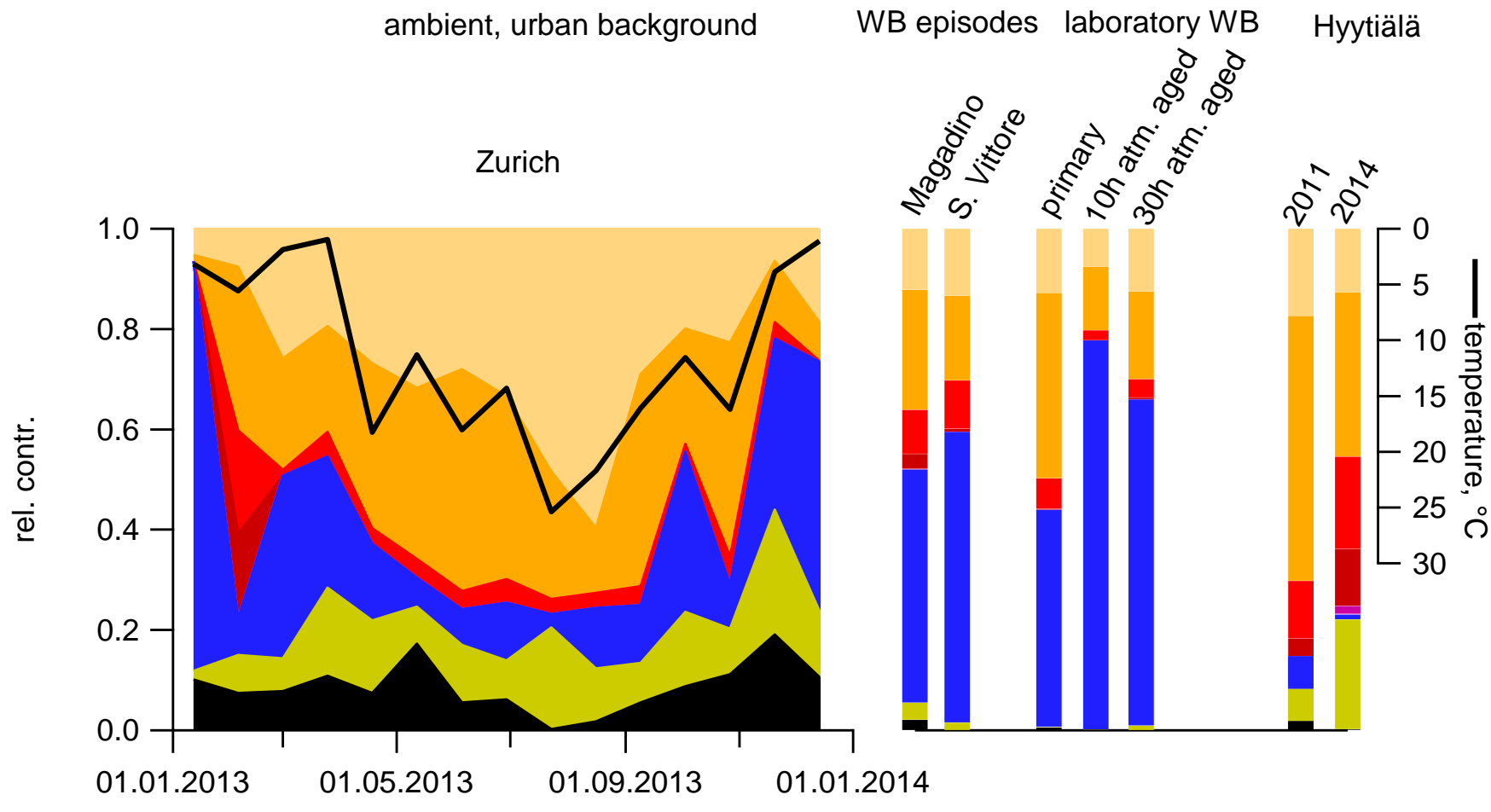

5 Figure S7: relative contributions of different compound classes to total signal. 